10-20-2014

\title{
Surface and Subsurface Attenuation of Trenbolone Acetate Metabolites and Manure-Derived Constituents in Irrigation Runoff on Agro- Ecosystems
}

Gerrad D. Jones

Peter V. Benchetler

Kenneth W. Tate

Edward P. Kolodziej

University of Washington Tacoma, koloj@uw.edu

Follow this and additional works at: https://digitalcommons.tacoma.uw.edu/ias_pub

\section{Recommended Citation}

Jones, Gerrad D.; Benchetler, Peter V.; Tate, Kenneth W.; and Kolodziej, Edward P., "Surface and Subsurface Attenuation of Trenbolone Acetate Metabolites and Manure-Derived Constituents in Irrigation Runoff on Agro-Ecosystems" (2014). SIAS Faculty Publications. 576.

https://digitalcommons.tacoma.uw.edu/ias_pub/576 


\section{Environmental Science Processes \& Impacts}

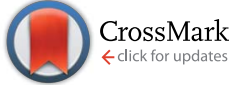

Cite this: Environ. Sci.: Processes Impacts, 2014, 16, 2507
Received 13th July 2014

Accepted 4th September 2014

DOI: $10.1039 / c 4 e m 00385 c$

\section{Surface and subsurface attenuation of trenbolone acetate metabolites and manure-derived constituents in irrigation runoff on agro- ecosystems $\uparrow$}

\begin{abstract}
Gerrad D. Jones, t $^{a}$ Peter V. Benchetler, ${ }^{a}$ Kenneth W. Tate ${ }^{b}$ and Edward P. Kolodziejcd
Although studies have evaluated the ecotoxicity and fate of trenbolone acetate (TBA) metabolites, namely $17 \alpha$-trenbolone $(17 \alpha-\mathrm{TBOH}), 17 \beta$-trenbolone $(17 \beta-\mathrm{TBOH})$, and trendione (TBO), their environmental transport processes remain poorly characterized with little information available to guide agricultural runoff management. Therefore, we evaluated TBA metabolite transport in representative agricultural systems with concurrent assessment of other manure-derived constituents. Leachate generated using manure from TBA-implanted cattle was applied to a subsurface infiltration plot $(4 \mathrm{~m})$ and surface vegetative filter strips (VFSs; 3, 4, and $5 \mathrm{~m}$ ). In the subsurface experiment, 17 $\alpha$-TBOH leachate concentrations were $36 \mathrm{ng} \mathrm{L^{-1 }}$ but decreased to $12 \mathrm{ng} \mathrm{L}^{-1}$ in initial subsurface discharge. Over 75 minutes, concentrations linearly increased to $23 \mathrm{ng} \mathrm{L}^{-1}\left(C / C_{0}=0.32-0.64\right)$. In surface experiments $(n=$ 4), $17 \alpha-\mathrm{TBOH}$ leachate concentrations ranged from $11-150 \mathrm{ng} \mathrm{L^{-1 }}$, remained nearly constant with time, but were attenuated by 70-90\% after VFS treatment with no statistical dependence on the VFS length. While attenuation clearly occurred, the observations of a highly mobile fraction of all constituents in both surface runoff and subsurface discharge suggest that these treatment strategies may not always be capable of achieving threshold discharge concentrations. To attain no observed adverse effect levels (NOAELs) in receiving waters, concurrent assessment of leachate concentrations and available dilution capacities can be used to guide target treatment performance levels for runoff management. Dilution is usually necessary to achieve NOAELs, and receiving waters with less than 70-100 fold dilution capacity are at the highest risk for steroidal endocrine disruption.
\end{abstract}

\section{Environmental impact}

Trenbolone acetate (TBA) is a potent androgenic steroid used to increase weight gain, and thus economic value, of beef cattle prior to slaughter. While several studies have qualitatively evaluated TBA metabolite transport based on their presence/absence in storm runoff, studies have not evaluated spatial and temporal dynamics of TBA transport in rangelands and irrigated pastures. Concentrations of TBA metabolites were measured before and after treatment on surface and subsurface experimental plots (i.e., 3-5 m). Over short time scales (2-75 minutes), surface partitioning was likely responsible for observed attenuation, but it was clear that non-equilibrium processes facilitated the rapid transport of at least some contaminant fraction. This work has implications for best management practices for agricultural runoff and identifies potential opportunities for optimization.

${ }^{a}$ Department of Civil and Environmental Engineering, University of Nevada-Reno, MS 0258, Reno, Nevada, 89557, USA

${ }^{b}$ Department of Plant Sciences, University of California-Davis, MS 1, Davis, California, 95616-8780, USA

'Interdisciplinary Arts and Sciences (UW Tacoma), University of Washington, WCG 424, Box 358436, 1900 Commerce Street, Tacoma, WA, 98402, USA. E-mail: koloj@ uw.edu; Fax: +1-253-692-5718; Tel: +1-253-692-5659

${ }^{d}$ Department of Civil and Environmental Engineering (UW Seattle), University of Washington, 201 More Hall, Box 352700, Seattle, 98195-2700, WA, USA

$\uparrow$ Electronic supplementary information (ESI) available: Additional material regarding experimental methods, soil partitioning calculations, and experimental data (Fig. S1-S5). See DOI: 10.1039/c4em00385c

\$ Current address: Eawag, Swiss Federal Institute of Aquatic Science and Technology, Überlandstrasse 133, 8600 Dübendorf, Switzerland.

\section{Introduction}

Trenbolone acetate (TBA) is a synthetic steroid hormone, which is pervasive in beef cattle production, that promotes weight gain and thus economic value of cattle. However, observations of endocrine disruption in surface waters affected by agricultural runoff have led to concerns over TBA use, in part due to the potent endocrine activity of the TBA metabolites $17 \alpha$-trenbolone $(17 \alpha-\mathrm{TBOH}), \quad 17 \beta$-trenbolone $(17 \beta-\mathrm{TBOH})$, and trendione (TBO) ${ }^{1-4}$ While the causative agents responsible for these observations remain unclear, these steroids may contribute to potential ecological hazards of growth promoter use in agroecosystems. ${ }^{1-3,5,6}$ Trace concentrations (e.g., 5-100 ng L ${ }^{-1}$ ) of 
$17 \alpha-\mathrm{TBOH}$ and $17 \beta-\mathrm{TBOH}$ can induce irreversible phenotypic sex reversal upon embryonic exposure and significant fecundity reduction in fish if exposure occurs during reproductive periods. ${ }^{7-10}$ Although no observed adverse effect levels (NOAELs) are not reported for TBA metabolites, a reasonable NOAEL estimate, based on estimates derived for other steroids, is $\sim 1 \mathrm{ng} \mathrm{\textrm {L } ^ { - 1 }}$ in receiving waters..$^{\mathbf{8 , 1 1 , 1 2}}$

Limited data exist that predict TBA metabolite fate and transport in rangeland and pasture systems. While several studies have evaluated transformation kinetics and documented the TBA metabolite occurrence in runoff from feedlot and tile-drained systems, ${ }^{\mathbf{1 3 - 1 9}}$ fate and transport can be differentially affected by system characteristics (e.g., bare soil vs. crops or natural vegetation) and management practices (e.g., CAFO lagoon vs. manure amended soils). For example, using soil columns, Schiffer et al. observed $\sim 82-92 \%$ attenuation of $17 \beta$-ТВОH after $\sim 10$ pore volumes, with subsequent high steroid recoveries upon solvent extraction of the soils indicating the importance of hydrophobic partitioning. ${ }^{20}$ Given their moderate affinities for organic carbon $\left(\log K_{\mathrm{oc}}=2.5-3.6\right),{ }^{21-24}$ equilibrium partitioning estimates suggest that the transport of TBA metabolites and other steroids should be dominated by sequestration to immobile organic phases and soils. ${ }^{25-30}$ However, some studies reported far higher mobility and concentrations that cannot be reconciled with equilibrium partitioning estimates. While Schiffer et al. ${ }^{20}$ observed substantial attenuation, $17 \beta-\mathrm{TBOH}$ breakthrough occurred nearly simultaneously with chloride, indicating rapid transport, similar to observations for estradiol and testosterone in soil columns. ${ }^{31}$ Despite partitioning predictions in soils, testosterone, $17 \beta$-estradiol, and TBA metabolites are detected at relatively high concentrations (e.g., $\left.160 \mathrm{ng} \mathrm{L}^{-1}\right)$ in ground water, the vadose zone, and surface waters. ${ }^{14,15,32,33}$ They also rapidly transport through the vadose zone to shallow $(<3 \mathrm{~m})$ tile drain systems after storms and can exhibit long-term (many weeks) persistence in heterogeneous aquatic systems. ${ }^{\mathbf{1 4 , 1 5}}$ Collectively, these observations suggest that multiple processes affect fate and transport, including possible association with colloids or dissolved organic matter that potentially facilitates transport or the existence of kinetic limitations to partitioning at low, environmentally relevant concentrations. These data indicate that steroids do retain unexpected mobility and persistence in the environment and that their fate is not always dominated by equilibrium hydrophobic partitioning.

Relative to transport, more data are available that characterize TBA metabolite fate processes (e.g., photolysis, sorption, transformations) in laboratory and field studies. ${ }^{13,19,22,34-37}$ Some studies qualitatively evaluated transport based on the presence/ absence of TBA metabolites in surface runoff or subsurface

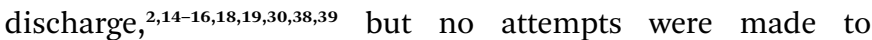
decouple TBA metabolite leaching and transport processes, both of which can strongly influence subsequent concentrations. This issue also confounds the extrapolation of laboratory data generated using synthetic solutions to field scales where leaching dynamics and non-equilibrium conditions strongly affect the steroid occurrence. ${ }^{20}$ To optimize agricultural runoff management, the relative contributions of leaching and transport processes should be evaluated independently. For example, if leaching dominates, adequate strategies to minimize the risks associated with TBA use might involve optimizing irrigation practices to minimize the leaching potential. Conversely, if transport dominates, management practices designed to inhibit transport by sequestering TBA metabolites on immobile phases should be implemented.

Given these complex behaviors and seemingly contradictory observations, investigating the TBA metabolite transport potential in agro-ecosystems is necessary to understand agricultural discharges of steroids to the aquatic environment and develop treatment strategies to attenuate potential hazards. Previously, we evaluated leaching processes using manure excreted by TBA-implanted animals during both rainfall and irrigation events and developed models to predict leaching potential under rainfall and irrigation scenarios. ${ }^{40}$ Therefore, our objective was to evaluate plot-scale subsurface and surface transport of TBA metabolites in agro-ecosystems with a focus on runoff management strategies. Specific study objectives were to: (1) quantify the transport potential of TBA metabolites in plotscale surface runoff and subsurface discharge; (2) compare TBA metabolite attenuation to that of other manure-derived constituents (i.e., total ammonia, orthophosphate, nitrate, nitrite, dissolved organic carbon (DOC), total coliforms, and $E$. coli); and (3) evaluate management strategies to control the transport of steroids and other manure-derived constituents in agro-ecosystems.

\section{Materials and methods}

\section{Site description}

Subsurface and surface plot-scale transport studies were conducted at the University of California Sierra Foothills Research and Extension Center (SFREC) near Browns Valley, CA. Soils were classified as Typic Haploxeralfs and Mollic Haploxeralfs with clay loam surface textures and clay subsoils. Soils generally extended to depths of $0.75-1.5 \mathrm{~m}$ above basic metavolcanic (greenstone) bedrock. Local vegetation on rangelands included naturalized annual grasses and forbs and native perennial grasses with a savanna/woodland over-story composed primarily of evergreen and deciduous oak trees. Vegetation on vegetative filter strips (VFSs) consisted of introduced forage species (e.g., perennial ryegrass, fescue, and red and white clover).

We evaluated subsurface transport of TBA metabolites and other manure constituents using a soil trench within SFREC's "Lewis-1" watershed (NAD 83 UTM 10S-645581E, 4348683N). ${ }^{41}$ This 34.6 ha watershed has not been grazed in $>10$ years and consists of blue-oak savanna with an average grade of $\sim 24 \%$. The soil trench was constructed in 1999 and consists of a vertical cut through the soil profile to bedrock. Aluminum collection trays ( $1 \mathrm{~m}$ horizontal width) were placed at various soil horizons (i.e., bottom of the $\mathrm{A}(8 \mathrm{~cm}), \mathrm{AB}(30 \mathrm{~cm}), \mathrm{Bt}(65 \mathrm{~cm})$, and $\mathrm{C}(110 \mathrm{~cm})$ horizons; Fig. 1) to capture lateral subsurface discharge. ${ }^{41}$ During precipitation, most flow discharges from the $\mathrm{AB}$ horizon $(60 \%)$ compared to other horizons, which individually discharge $10-17 \%$ of the flow. ${ }^{41}$ Preferential flow 
a)
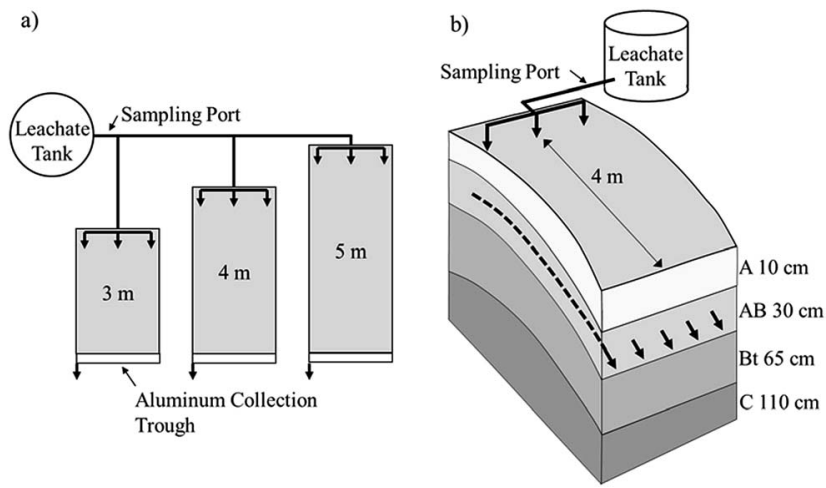

Fig. 1 Schematic diagram of (a) vegetative filter strips of $2 \mathrm{~m}$ width $\times$ 3,4 , and 5 m length. Leachate was applied uniformly across each VFS and runoff was collected in aluminum trays. The same leachate application system was used for subsurface experiments (b). Aluminum trays (width $=1 \mathrm{~m}$ ) were placed at different soil horizon interfaces to capture discharge. The horizon name and depth are listed.

through the $\mathrm{AB}$ horizon is a result of lower clay content as well as the presence of well-formed spheroidal soil aggregates and larger pores (e.g. decayed root channels). ${ }^{41}$

We evaluated overland transport of TBA metabolites and other manure-derived constituents on VFSs of different lengths (i.e., 3, 4, $5 \mathrm{~m}$ length $\times 2 \mathrm{~m}$ width) constructed at SFREC in 2006 (NAD 83 UTM 10S-645107E, 4344613N; Fig. 1 and S1†). The average grade was $\sim 6 \%$, and each VFS was bordered with $2 \mathrm{~mm}$ thick $\times 45 \mathrm{~cm}$ wide aluminum sheeting buried to $30 \mathrm{~cm}$ below the soil surface to prevent water exchange. Each VFS was equipped with a downgradient sample collection trough constructed of concrete and aluminum where the runoff volume was measured. Of the eighteen VFSs available, we selected three based on their low infiltration rates and lack of preferential flow paths to evaluate transport in surface runoff following application of a TBA-metabolite containing leachate solution.

\section{Leachate generation}

Leachate solutions representative of agricultural runoff were generated using manure collected from Hereford/Angus cross heifers and steers (steer calves $[n=3]$ or yearling heifers $[n=4]$, 145-350 kg, 6-18 months old) that were implanted with Revalor $\mathrm{G}$ (40 mg TBA and $8 \mathrm{mg}$ estradiol, for use on rangeland cattle) as previously described. ${ }^{40}$ Briefly, manure was collected over $24-72$ hours, stored onsite in a closed container, then immediately used in experiments to generate leachate. When needed, animals were re-implanted following manufacturer protocols. Animals were handled in accordance with guidelines prescribed by the University of California, Davis Animal Care and Use Committee. To generate leachate solutions, $20-40 \mathrm{~L}(20-40 \mathrm{~kg})$ of manure from TBA implanted heifers or steers was added to a $1500 \mathrm{~L}$ tank. In general, nutrient concentrations in this leachate were similar to published concentrations $\left(0.05-7.2 \mathrm{mg} \mathrm{NH}_{3}-\mathrm{N}\right.$ per L, 0.17-4.29 mg $\mathrm{PO}_{4}$-P per L, $1.0 \times 10^{5}-1.8 \times 10^{6} \mathrm{CFU}$ per $100 \mathrm{~mL}$ ) in agricultural runoff and to runoff concentrations from other experiments conducted on irrigated pasture at
SFREC (Fig. S2 $\dagger$ ). ${ }^{42-47}$ The tank was placed upslope of the soil trench or VFS system and filled with irrigation water (Browns Valley Irrigation District; $\mathrm{pH}=7.6, \mathrm{DOC}=5.7 \pm 0.1 \mathrm{mg} \mathrm{L}^{-1}$ ). Prior to experiments, the solution was allowed to equilibrate for 24 hours (Fig. 1 and S1†). When applied, leachate water was drawn from $\sim 0.3 \mathrm{~m}$ above the bottom of the tank to minimize the application of settled solids at the bottom of the tank.

\section{Subsurface discharge}

On May 24, 2013, the soil $4 \mathrm{~m}$ upslope of the soil trench was presaturated for 30 minutes with "clean" irrigation water. This step was necessary to promote subsurface discharge and to conserve the limited volume of leachate solution available to investigate transport processes. After a 30 minute drying period, the leachate solution was evenly applied to the test plot using a 1.5 $\mathrm{m}$ perforated pipe positioned $4 \mathrm{~m}$ above the trench at a rate of $\sim 15 \mathrm{~L} \mathrm{~min}^{-1}$. Over the $4 \mathrm{~m}$ travel distance, the wetting front spread $8.5 \mathrm{~m}$ laterally. The estimated wetted area was $19.5 \mathrm{~m}^{2}$ for a bulk application rate of $4.6 \mathrm{~cm} \mathrm{~h}^{-1}$ (1.8 cfs per ac), which is near average for central California irrigation practices, but high for natural rainfall. ${ }^{45}$ At this application rate, the saturated retention time of the system was $\sim 2$ minutes, and the average discharge flow rate in the $\mathrm{AB}$ horizon was $0.63 \mathrm{~L} \mathrm{~min}^{-1}$. While no surface runoff was generated, discharge from the A horizon occurred near the end of the experiment and was estimated to be $5 \%$ of the $\mathrm{AB}$ horizon flow. Flow was only collected from the $\mathrm{AB}$ horizon. The discharge from the $\mathrm{AB}$ horizon accounted for $\sim 4.5 \%$ of the total flow applied. Concurrent leachate and discharge samples from the $\mathrm{AB}$ horizon were collected in $4 \mathrm{~L}$ amber glass bottles at 15 minute time intervals for 75 minutes; this experimental period was also used in VFS studies to facilitate direct comparison. For both soil trench and VFS studies, the available tank volume defined the application period and thus the sampling period, as runoff ceased when the tank emptied.

Samples were immediately pressure filtered $(0.7 \mu \mathrm{m}$ AP40 filters, Millipore, Billerica, MA, USA) on site, and a $3 \mathrm{~L}$ subsample was used for $17 \alpha-\mathrm{TBOH}, 17 \beta-\mathrm{TBOH}$, and ТВO analysis. ${ }^{18,19}$ Of the remaining volume, $95 \mathrm{~mL}$ was vacuum filtered (0.45 $\mu \mathrm{m}$ GB-140, Advantec MFS Inc., Dublin, CA, USA) and split for nutrient (i.e., total ammonia $\left(\mathrm{NH}_{3}\right)-\mathrm{N}$, nitrate- $\mathrm{N}$, nitrite- $\mathrm{N}$, and orthophosphate $\left.\left(\mathrm{PO}_{4}\right)-\mathrm{P} ; 20 \mathrm{~mL}\right)$ and DOC $(75 \mathrm{~mL})$ analysis (see ref. 40 for nutrient and DOC analysis). After field processing, subsamples were transported to the laboratory on ice. For TBA metabolites, upon arrival to the laboratory ( $\sim 3$ hours after sample collection) each subsample was subsequently split into $1 \mathrm{~L}$ aliquots for triplicate analysis and spiked with $1 \mathrm{~mL}$ of 100 $\mu \mathrm{g} \mathrm{L}^{-1}$ (i.e., $100 \mathrm{ng}$ ) of $17 \beta-\mathrm{TBOH}^{-\mathrm{d}_{3}}$ internal standard in methanol, then extracted with $6 \mathrm{~mL}$ C-18 solid phase extraction (SPE) cartridges (Restek, Bellefonte, PA, USA; $Q<10 \mathrm{~mL} \mathrm{~min}^{-1}$ ). SPE cartridges were stored at $1{ }^{\circ} \mathrm{C}$ prior to steroid analysis. Nutrient and TOC samples were stored at $1{ }^{\circ} \mathrm{C}$ and analyzed within 24 hours. 


\section{Surface runoff}

We evaluated the transport of TBA metabolites and other manure constituents on VFS on four different dates (24 May, 31 May, 8 June, and 3 July, 2012). All experiments were conducted similarly, with the exception of the experimental duration and the number of samples collected. The data were consistent among all experiments, but only the most comprehensive dataset (July 3) is presented here (see ESI $\dagger$ for data on other trials). To promote surface runoff generation, each VFS was presaturated for 30 minutes with "clean" irrigation water prior to leachate application. Leachate (prepared as previously described) was applied simultaneously and uniformly to the three VFS plots through a perforated pipe (Fig. 1). The application rate per VFS over the 75 minute trial was $4 \mathrm{~L} \mathrm{~min}^{-1}$. The resulting area-normalized irrigation rates for the 3,4 , and $5 \mathrm{~m}$ VFS were $4.0 \mathrm{~cm} \mathrm{~h}^{-1}$ (1.6 cfs per ac), $3.0 \mathrm{~cm} \mathrm{~h}^{-1}$ (1.2 $\mathrm{cfs}$ per ac), and $2.4 \mathrm{~cm} \mathrm{~h}^{-1}$ ( $0.9 \mathrm{cfs}$ per ac) respectively, which are typical for central California. ${ }^{45}$ Average runoff rates for the 3,4 , and $5 \mathrm{~m}$ VFSs were $1.7,1.4$, and $1.0 \mathrm{~cm} \mathrm{~h}^{-1}$, respectively, suggesting $\sim 40 \%$ infiltration and $60 \%$ runoff during these trials. Once runoff began (at 2, 3, and 5 minutes for 3, 4, and $5 \mathrm{~m}$ VFSs, respectively), $4 \mathrm{~L}$ samples were collected from the sampling port of the common header pipe and each VFS collection trough at 15 minute intervals (Fig. 1). Prior to pressure filtration, a $100 \mathrm{~mL}$ subsample was collected for total coliform and E. coli analysis (see ref. 40 for analysis procedures). The remaining sample was split into subsamples and processed for TBA metabolites, nutrients, and DOC analysis as described.

In addition to aqueous samples, we collected $10 \mathrm{~cm}$ soil cores $(n=9)$ throughout each VFS after leachate application following the last trial to estimate the mass of TBA metabolites sorbed to surface soils. The above ground biomass was removed from each core, which were homogenized, immediately placed on ice, and transported to the laboratory. Within 24 hours, samples ( $n=6, \sim 100$ g-dry weight) were sonicated in methanol $(100 \mathrm{~mL})$, rinsed with deionized water $(100 \mathrm{~mL})$, and centrifuged (3600 rpm, 10 minutes). The supernatant was decanted into $4 \mathrm{~L}$ amber glass bottles. This process was repeated 3 times, after which the supernatant was diluted to $4 \mathrm{~L}$. The samples were then spiked with $1 \mathrm{~mL}$ of $100 \mu \mathrm{g} \mathrm{L}{ }^{-1} 17 \beta-\mathrm{TBOH}^{-\mathrm{d}_{3}}$ and loaded onto SPE cartridges.

\section{Sample analysis}

TBA metabolites were processed, derivatized, and analyzed by GC/MS/MS (Agilent 6890N Gas Chromatograph, Santa Clara, CA, USA; Waters Quattro Micromass spectrometer, Milford, MA, USA) for $17 \alpha-\mathrm{TBOH}, \quad 17 \beta-\mathrm{TBOH}$, and $\mathrm{TBO}^{18,19,40} \mathrm{QA} / \mathrm{QC}$ measures included field blanks (i.e., irrigation water), background samples (i.e., runoff prior to leachate application), and laboratory spikes (100 ng L ${ }^{-1}$ of $17 \alpha-\mathrm{TBOH}, 17 \beta-\mathrm{TBOH}$, and TBO) analyzed identically to other samples. With the exception of TBO, all field blanks and background samples were at or below the limit of detection (i.e., $0.5 \mathrm{ng} \mathrm{L}^{-1} 17 \alpha$-TBOH and TBO

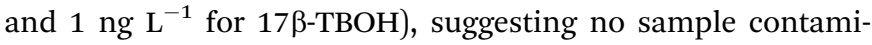
nation. TBO was not detected in irrigation water, but TBO analysis in surface runoff was complicated by co-eluting interference precluding quantification. The average $17 \beta-\mathrm{TBOH}-$ $\mathrm{d}_{3}$ recovery for samples was low but consistent at $45 \pm 7 \%(n=$ 142), and reported concentrations were corrected using $17 \beta$ $\mathrm{TBOH}-\mathrm{d}_{3}$ recoveries, but not spike recoveries. While matrix interference of the leachate solution $\left(\sim 60 \mathrm{mg} \mathrm{L}{ }^{-1}\right.$ DOC) was likely responsible for low recoveries of the isotopic standard, $17 \alpha-\mathrm{TBOH}, 17 \beta-\mathrm{TBOH}$, and TBO $100 \mathrm{ng} \mathrm{L^{-1 }}$ spike recoveries were $112 \pm 19 \%, 102 \pm 13 \%$, and $92 \pm 34 \%$, respectively $(n=10)$.

\section{Results and discussion}

\section{Subsurface discharge}

We evaluated subsurface transport and attenuation processes of manure constituents by comparing leachate and discharge concentrations from the $\mathrm{AB}$ soil-horizon through time. Given the rapid transport of water (approximately $3 \mathrm{~cm} \mathrm{~s}^{-1}$ linear velocities in these systems) in both the shallow subsurface system and VFS plots (as described later), we expect that contaminant attenuation arises primarily from partitioning mechanisms, as there existed insufficient hydraulic retention time for transformation mechanisms to affect concentrations. In the subsurface experiment, average leachate concentrations of $17 \alpha$-ТВOH and $17 \beta$-ТВOH were $36 \pm 5 \mathrm{ng} \mathrm{L}^{-1}$ and $3 \pm 2 \mathrm{ng} \mathrm{L}^{-1}$, respectively. TBO was detected once at $5 \mathrm{ng} \mathrm{L}^{-1} .17 \beta-\mathrm{TBOH}$ was not detected in subsurface discharge, while TBO was detected once in discharge at $3 \mathrm{ng} \mathrm{\textrm {L } ^ { - 1 }}$. 17 $\alpha$-TBOH was detected in all discharge samples, linearly increasing from an initial concentration of $12 \pm 2 \mathrm{ng} \mathrm{L}^{-1}$ ( $65 \%$ removal; i.e., $1-C / C_{\mathrm{o}}$ ) to $23 \pm 5 \mathrm{ng}$ $\mathrm{L}^{-1}$ (32\% removal) over 75 minutes (Fig. 2). Based on this trend, complete breakthrough (i.e., $C / C_{\mathrm{o}}=1$ ) was expected to occur near 160 minutes. Thus, the sorption capacity under these conditions was expected to be exhausted after 160 minutes, after which the mass leached/applied will equal the mass transported. Using a mass balance approach, estimates for the $17 \alpha-$ TBOH soil concentration at 160 minutes range from

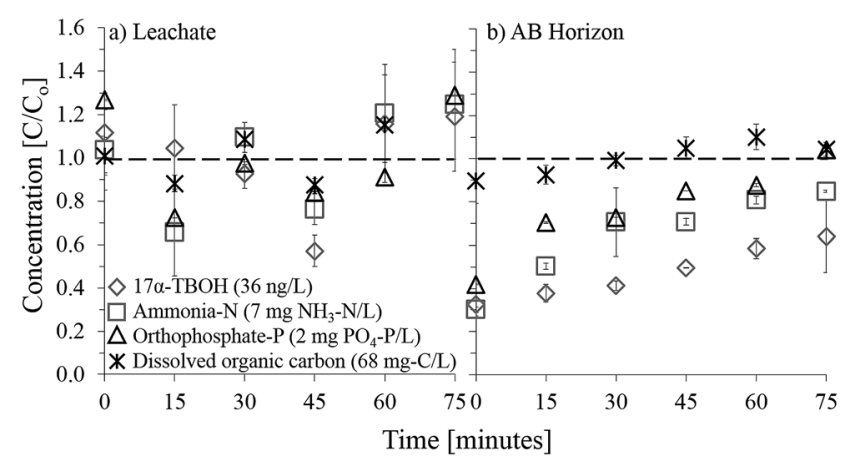

Fig. 2 Normalized concentrations of measured constituents in (a) leachate and (b) subsurface discharge from the AB soil horizon after 4 $m$ of transport in the vadose zone. All concentrations were normalized to the average leachate concentration (specific values provided in the legend for each constituent). For leachate and runoff samples, $t=$ 0 minute corresponds to the moment $A B$ horizon discharge first occurred (hydraulic retention time $=2$ minutes). Error bars represent 95\% confidence intervals $(n=3)$. 
Table 1 Parameter values used to calculate the partitioning coefficient $\left(K_{\mathrm{D}}\right)$ between $17 \alpha-\mathrm{TBOH}$ and soils and the mass of ammonia, orthophosphate, and dissolved organic carbon (DOC) within the AB horizon of the soil trench under three different scenarios. Soil concentrations represent the constituent mass sorbed at exhaustion ${ }^{c}$

\begin{tabular}{|c|c|c|c|}
\hline Scenario & A & B & $\mathrm{C}$ \\
\hline Flow $\left(\mathrm{L} \mathrm{min}^{-1}\right)$ & 15 & 5.4 & 0.63 \\
\hline AB soil volume $(\mathrm{L})$ & 5850 & 5850 & 1200 \\
\hline AB soil mass $\left(\mathrm{kg}\right.$, based on $\left.\rho_{\mathrm{b}}=1.5 \mathrm{~kg} \mathrm{~L}^{-1}\right)$ & 8780 & 8780 & 1800 \\
\hline $17 \alpha-\mathrm{TBOH}$ soil concentration $\left(\mathrm{ng} \mathrm{kg}^{-1}\right)$ & 3.4 & 1.2 & 0.7 \\
\hline $17 \alpha$-TBOH system $K_{\mathrm{D}}\left(\mathrm{L} \mathrm{kg}^{-1}\right)^{a}$ & 0.09 & 0.03 & 0.02 \\
\hline $17 \alpha$-ТВOH sorption capacity used ${ }^{b}$ & $0.9 \%$ & $0.3 \%$ & $0.2 \%$ \\
\hline Ammonia soil concentration (mg $\mathrm{NH}_{3}-\mathrm{N}$ per $\mathrm{kg}$ ) & 0.32 & 0.12 & 0.07 \\
\hline Orthophosphate soil concentration ( $\mathrm{mg} \mathrm{PO}_{4}-\mathrm{P}$ per kg) & 0.07 & 0.03 & 0.02 \\
\hline DOC soil concentration ( $\mathrm{mg} \mathrm{C}$ per $\mathrm{kg}$ ) & 0.18 & 0.06 & 0.04 \\
\hline
\end{tabular}

${ }^{a}$ See ESI for calculation. ${ }^{b}$ System $K_{\mathrm{D}}$ : calculated $K_{\mathrm{D}}$ (based on soil properties, Table 2) ratio. ${ }^{c} \rho_{\mathrm{b}}=$ bulk density.

0.7-3.4 $\mathrm{ng} \mathrm{kg}^{-1}$ (Table 1, see ESI $\dagger$ for calculation). By dividing the soil concentration by the aqueous concentration $\left(36 \mathrm{ng} \mathrm{L}^{-1}\right)$, we estimated that a partitioning coefficient $\left(K_{\mathrm{D}}\right)$ range of $0.02-$ $0.09 \mathrm{~L} \mathrm{~kg}^{-1}$ (Table 1) in this system, which is $100-500$ times smaller than the $K_{\mathrm{D}}$ calculated using soil physical and chemical properties $\left(10 \mathrm{~L} \mathrm{~kg}^{-1}\right.$, Table 2$)$. This suggested that $<1 \%$ of the total sorption capacity was used under experimental conditions and that $17 \alpha-\mathrm{TBOH}$ attenuation within the shallow subsurface is dominated by non-equilibrium partitioning. We speculate that in agro-ecosystems receiving continual animal waste applications, a higher fraction of sorption capacity will be used, but similar partitioning mechanisms and non-equilibrium conditions might still be expected.

Similar to $17 \alpha-\mathrm{TBOH}$, the transport of nutrients and DOC was rapid and coincided with the initial discharge (Fig. 2). For

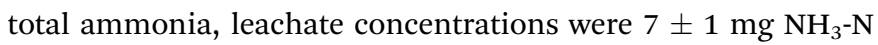
per L. Initial subsurface discharge concentrations were $2.1 \pm 0.1$ $\mathrm{mg} \mathrm{NH}_{3}-\mathrm{N}$ per $\mathrm{L}(70 \%$ removal) and increased linearly throughout the experiment to $5.9 \pm 0.3 \mathrm{mg} \mathrm{NH}_{3}-\mathrm{N}$ per $\mathrm{L}(16 \%$ removal). Complete breakthrough was expected to occur near 90 minutes. For orthophosphate, leachate concentrations were 2.5 $\pm 0.4 \mathrm{mg} \mathrm{PO}_{4}-\mathrm{P}$ per $\mathrm{L}$, and initial runoff concentrations were 0.8 $\pm 0.1 \mathrm{mg} \mathrm{PO}-\mathrm{P}$ per L (68\% removal). After increasing linearly through time, complete breakthrough was reached near 70 minutes ( $0 \%$ removal). For DOC, the average leachate $(61 \pm 6$ $\mathrm{mg} \mathrm{C}$ per L) and runoff ( $61 \pm 4 \mathrm{mg} \mathrm{C}$ per L) concentrations were statistically identical $(P=0.92)$ throughout the experiment. However, as with the other constituents, discharge concentrations increased linearly through time and reached complete breakthrough at 30 minutes, suggesting likely partitioning and DOC exchange during the trial (Fig. 2). Using estimated breakthrough times for ammonia (90 minutes), orthophosphate (70 minutes), and DOC (30 minutes), the estimated increase in soil concentration of each constituent upon exhausting the sorption capacity was $0.07-0.32 \mathrm{mg} \mathrm{N} \mathrm{NH}_{3}-\mathrm{N}$ per $\mathrm{kg}, 0.02-0.07 \mathrm{mg} \mathrm{PO}_{4}-\mathrm{P}$ per kg, and 0.04-0.18 $\mathrm{mg} \mathrm{C}$ per $\mathrm{kg}$ (see $\mathrm{ESI} \uparrow$ for calculation). We did not estimate system partitioning coefficients for ammonia, orthophosphate, or dissolved carbon due to the non-linearity of nutrient isotherms and the possibility of DOC exchange.

Several studies reported rapid transport of agricultural steroids through soils, ${ }^{20,25-27,31,48}$ potentially due to mechanisms like hydrophobic partitioning to colloids. ${ }^{20,23,48-50}$ However, the estimated fraction of $17 \alpha-\mathrm{TBOH}$ associated with DOC was low (i.e., $F_{\mathrm{c}}=0.2 \%$, Table 2, see ESI $\dagger$ ), suggesting negligible colloidal transport, although we recognize that $K_{\text {oc }}$ can be poorly correlated with steroid absorption to organic colloids. ${ }^{49}$ Rapid transport has also been attributed to non-equilibrium partitioning, as time scales for hydrophobic equilibrium may reach 24 hours. ${ }^{25-27}$ Thus, attenuation via partitioning to soils may be somewhat ineffective in systems with relatively short (e.g. minutes to hours) hydraulic retention times. Furthermore, partitioning is affected by rates of advective transport. If advective transport dominates (i.e., increasing Peclet number $[\mathrm{Pe}])$, the attachment efficiency on solid surfaces decreases, especially when Pe $>20 .{ }^{51}$ For $17 \alpha-\mathrm{TBOH}$, the estimated Pe was

Table 2 Physical and chemical properties of the soils at subsurface (AB horizon, $\mathrm{pH}=5.7$ ) and surface (vegetative filter strips, VFS, pH $=6.8$ ) experimental sites. Abbreviations include bulk density $\left(\rho_{\mathrm{b}}\right)$, porosity $(\varphi)$, cation exchange capacity $(C E C)$, fraction of soil organic carbon $\left(f_{\text {oc }}\right)$, $17 \alpha-$ trenbolone $(17 \alpha-\mathrm{TBOH})$ soil partitioning coefficient $\left(K_{\mathrm{D}}\right)$, estimated $17 \alpha-\mathrm{TBOH}$ retardation factor $(R)$, and the fraction of $17 \alpha-\mathrm{TBOH}$ dissolved in water $\left(F_{\mathrm{D}}\right)$, sorbed to soil $\left(F_{\mathrm{S}}\right)$, and sorbed to dissolved organic carbon $\left(F_{\mathrm{C}}\right)$. See ESI $\dagger$ for parameter calculation

\begin{tabular}{|c|c|c|c|c|c|c|c|c|c|c|c|c|}
\hline Soil & $\%$ Sand & $\%$ Silt & \% Clay & $\rho_{\mathrm{b}}\left[\mathrm{g} \mathrm{cm}^{-3}\right]$ & $\varphi[-]$ & $\begin{array}{l}\mathrm{CEC}^{a} \\
\text { [meq. per } 100 \mathrm{~g}]\end{array}$ & $f_{\mathrm{oc}}[\%]$ & $K_{\mathrm{D}}^{b}\left[\mathrm{~L} \mathrm{~kg}^{-1}\right]$ & $R^{c}[-]$ & $F_{\mathrm{D}}[\%]$ & $F_{\mathrm{S}}[\%]$ & $F_{\mathrm{C}}[\%]$ \\
\hline $\mathrm{AB}$ & 35 & 56 & 9 & 1.5 & 0.47 & $10.0 / 11.5$ & 1.7 & 10 & 33 & 5.5 & 94.3 & 0.2 \\
\hline VFS & 27 & 58 & 15 & 2 & 0.29 & $24.0 / 22.2$ & 2.9 & 17 & 119 & 1.2 & 98.7 & 0.1 \\
\hline
\end{tabular}

${ }^{a}$ CEC calculated by summing $\mathrm{Ca}^{2+}, \mathrm{Mg}^{2+}, \mathrm{Na}^{+}$, and $\mathrm{K}^{+}$(left of slash) and extracting $\mathrm{NH}_{4}^{+}$(right of slash). ${ }^{b} K_{\mathrm{D}}$ estimates based on the product of $f_{\mathrm{oc}}$ and $K_{\mathrm{oc}}\left(10^{2.77} \mathrm{~L} \mathrm{~kg}^{-1}\right) \cdot{ }^{22}$ Estimated from $\rho_{\mathrm{b}}, \varphi$, and $K_{\mathrm{D}}$. 
$>100$, suggesting that advective transport dominated at this scale. Although transport of $17 \alpha-\mathrm{TBOH}$ and other constituents were clearly retarded in the shallow subsurface, high advective transport rates and short hydraulic retention times likely best explain the observed data.

\section{Surface runoff}

We evaluated surface transport and attenuation processes of steroids, nutrients, DOC, and coliforms on VFS systems using similar methodologies. Although the same VFSs were used in all 4 trials, TBA metabolites were not detected in runoff during the saturation processes immediately prior to leachate application, indicating no analyte carryover between trials (Fig. 3). On average, $17 \alpha-\mathrm{TBOH}$ and TBO leachate concentrations were $34 \pm$

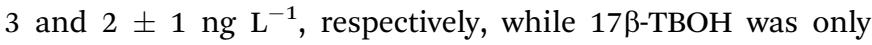
sporadically detected in both leachate and runoff at concentrations $<2 \mathrm{ng} \mathrm{L^{-1 }}$. 17 $\alpha$-TBOH concentrations were statistically greater in leachate than on VFS (one-way ANOVA, $F(19,29)=$ 21.5, $P<0.001$ ) but were not statistically different (based on Tukey's HSD post hoc test) in runoff among all VFSs (Fig. 3). Little effect of VFS length was evident at these scales, as average runoff concentrations of $17 \alpha$-ТBOH were $8 \pm 3,11 \pm 2$, and $9 \pm$ $1 \mathrm{ng} \mathrm{\textrm {L } ^ { - 1 }}$ from 3, 4, and $5 \mathrm{~m}$ VFSs, respectively. Similarly, the $17 \alpha$-TBOH removal (i.e., $1-C / C_{\mathrm{o}}$ ) performance for the VFS plots averaged $76 \pm 8 \%, 69 \pm 7 \%$, and $72 \pm 3 \%$ from 3,4 , and $5 \mathrm{~m}$ VFSs, respectively (Fig. 3). Little data are published on steroid removal efficiencies on VFS; however, these observations are similar to reported $17 \alpha-\mathrm{TBOH}$ removal in medium-scale irrigated pasture experiments (83\%) and $17 \beta$-estradiol removal on $3.1 \mathrm{~m}$ VFS (79\%). ${ }^{47,52}$ During both high and low volume/intensity rainfall events, we observed 95\% removal, which was relatively constant throughout the events, of $17 \alpha-$-TBOH using the same VFSs. ${ }^{47}$ These data coupled with the data presented within

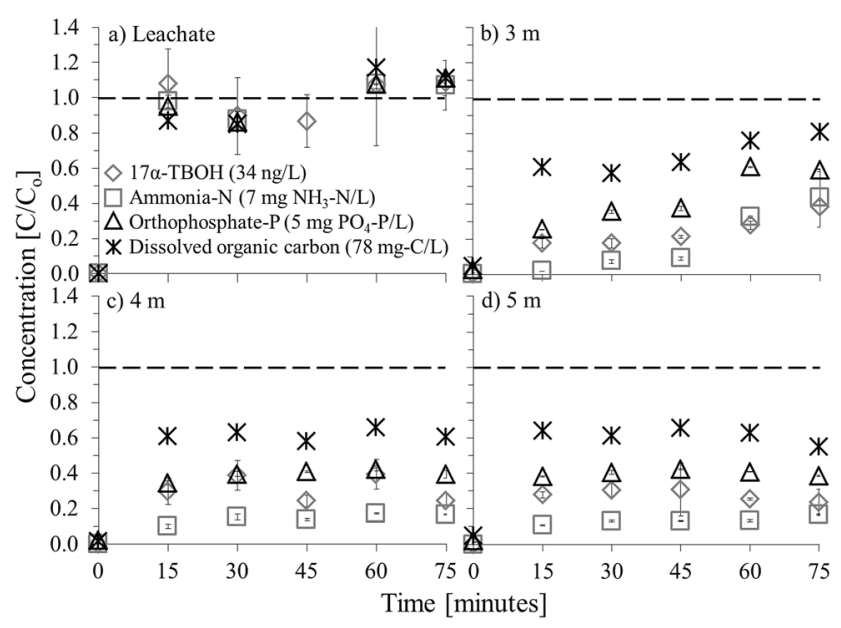

Fig. 3 Relative concentrations of manure-derived constituents in (a) leachate, and surface runoff from (b) $3 \mathrm{~m}$, (c) $4 \mathrm{~m}$, and (d) $5 \mathrm{~m}$ vegetative filter strips. All concentrations were normalized to the average leachate concentration (provided in the legend). Values reported at $t=$ 0 represent background concentrations. The first runoff samples were collected at $t=15$ minutes. Error bars represent 95\% confidence intervals $(n=3)$ and are not present for DOC. suggest that VFS are highly effective at attenuating TBA metabolites and steroid hormones transported in agricultural runoff.

Similar to subsurface experiments, we expected $17 \alpha-\mathrm{TBOH}$ concentrations in surface runoff to increase with time until complete breakthrough occurred. For all VFSs, partial breakthrough of $17 \alpha$-TBOH occurred rapidly $\left(C / C_{\mathrm{o}} \approx 0.25\right.$ in initial samples), indicating the existence of a highly mobile fraction of $17 \alpha-$ TBOH mass, again likely equilibrium limited or DOCassociated (78 $\mathrm{mg} \mathrm{L}^{-1}$ DOC in leachate). Control and management of this mobile fraction is expected to be especially challenging, as its rapid transport and apparently limited interaction with treatment system materials may place an upper boundary on the effectiveness of sequestration-based treatment strategies. However, unlike subsurface observations, concentrations in VFS runoff were surprisingly constant over time, especially for the 4 and $5 \mathrm{~m}$ VFSs (Fig. 3, 4, S2 and S3†), indicating slower saturation of attenuation capabilities and more efficient and consistent steroid attenuation on the VFSs relative to the subsurface system. We suspect this is a result of the increased productivity and complex heterogeneous environments on the VFS $\mathrm{O}$ horizon compared to the subsurface $\mathrm{AB}$ horizon. VFSs are irrigated and actively maintained throughout summer months and are characterized by year-round vegetative growth, unlike the soil trench watershed where vegetative growth is limited by seasonal aridity. Thus, biological activity and production of near-surface organic matter is likely substantially higher in VFS systems. Given the short hydraulic retention time (2-5 minutes), photolysis or microbial transformation processes, which occur on hours-days time scales, probably have minimal contribution to observed attenuation.

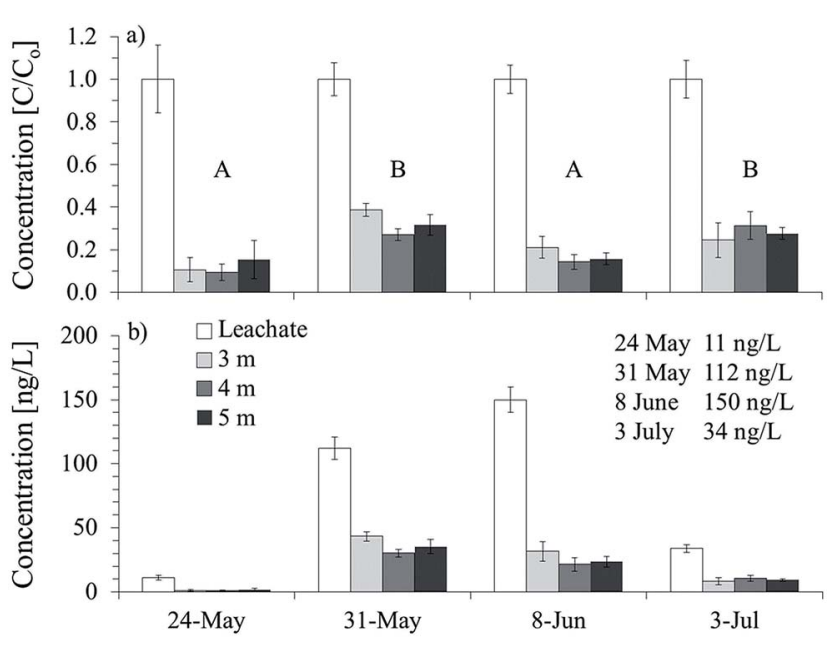

Fig. 4 Average (a) normalized runoff concentrations (i.e., $C / C_{0}$ ) and (b) actual runoff concentrations of $17 \alpha-\mathrm{TBOH}$ during four vegetative filter strip (VFS) runoff experiments. Relative concentrations were normalized based on the average contaminant concentration within leachate (provided in the legend). The average normalized-concentrations were statistically different based on Tukey's HSD test following a oneway ANOVA $(F(3,14)=39.1, P<0.001)$ if events did not share letters (i.e., A, B) with other events (a). Error bars represent 95\% confidence intervals $(n=6-30)$. 
Physical filtration, sorption, subsurface infiltration, and deposition are typically cited as the primary mechanisms of nutrient ( $\mathrm{N}$ and $\mathrm{P}$ ), pathogen, herbicide, and veterinary antibiotic removal from VFSs. ${ }^{4,53-56}$ Because source leachate concentrations were near constant throughout the duration of the experiment and leachate was continuously applied, infiltration cannot explain the observed concentration decreases. Furthermore, because of the tank design, the discharge of settlable solids in applied leachate was minimized, thus precluding sedimentation as a major removal mechanism. Instead, sequestration (either through sorption or filtration) within aboveground biomass or O-horizon constituents likely explained TBA metabolite removal. The presence of surface duff, biofilms, and an active rhizosphere may facilitate filtration and/or increase the hydrophobic partitioning capacity and increase the attenuation potential in VFSs. ${ }^{57}$ To verify the TBA metabolite loss via soil partitioning, we extracted soil samples collected before and after leachate application on July 3 . However, TBA metabolites were not detected in these samples, possibly because soils were extracted 24 hours after sample collection. With half-lives as short as 4 hours under warm, moist conditions, transformation prior to extraction may have occurred, ${ }^{35}$ limiting our ability to directly probe the importance of soil partitioning. Additional analysis of near surface soils and organic materials is necessary to characterize removal mechanisms for TBA metabolites and other runoff constituents from VFSs.

Concentrations of total ammonia, orthophosphate, and DOC within the irrigation water that was used to make the leachate solution were $0.022 \pm 0.005,0.011 \pm 0.005$, and $1.5 \mathrm{mg} \mathrm{L}^{-1}$, respectively, but increased considerably in leachate to $7 \pm 1 \mathrm{mg}$ $\mathrm{NH}_{3}-\mathrm{N}$ per $\mathrm{L}$ and $5 \pm 1 \mathrm{mg} \mathrm{PO}_{4}-\mathrm{P}$ per $\mathrm{L}$, and $78 \pm 10 \mathrm{mg} \mathrm{C}$ per L, respectively. Nitrate and nitrite were not detected in any

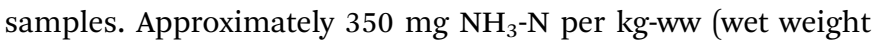
manure), $250 \mathrm{mg} \mathrm{PO}_{4}-\mathrm{P}$ per kg-ww, and $3900 \mathrm{mg} \mathrm{C}$ per kg-ww leached into the irrigation water during the 24 hour contact time. Total coliforms and $E$. coli were not detected in irrigation water, and while $E$. coli was not detected in runoff from VFSs prior to leachate application, an average of $4.0 \times 10^{6} \mathrm{CFU}$ per $100 \mathrm{~mL}$ of total coliforms was present prior to trials. For total coliforms and $E$. coli, leachate concentrations increased to $8.7 \times$ $10^{7}$ and $7.9 \times 10^{7} \mathrm{CFU}$ per $100 \mathrm{~mL}$, respectively, following contact with manure (Fig. S5†). Similar concentrations of ammonia, orthophosphate, and coliforms have been reported

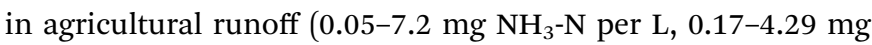
$\mathrm{PO}_{4}$-P per L, $1.0 \times 10^{5}-1.8 \times 10^{6} \mathrm{CFU}$ per $100 \mathrm{~mL}$ ) suggesting that the leachate is representative of agricultural runoff. ${ }^{42-46}$ Compared to $17 \alpha-\mathrm{TBOH}$, nutrients and DOC occurrence in VFS runoff followed similar spatial and temporal dynamics (Fig. 3, S3, and S4 $\dagger$ ). Average ammonia and orthophosphate runoff concentrations on 3,4 , and $5 \mathrm{~m}$ VFSs were $1 \pm 1 \mathrm{mg} \mathrm{NH} \mathrm{N}_{3}-\mathrm{N}$ per $\mathrm{L}$ and $2 \pm 1 \mathrm{mg} \mathrm{PO}_{4}-\mathrm{P}$ per $\mathrm{L}$ for all three VFSs while DOC concentrations were $50 \pm 9,48 \pm 2$, and $48 \pm 3 \mathrm{mg} \mathrm{L}^{-1}$, respectively. Removal efficiencies for the 3,4 , and $5 \mathrm{~m}$ VFSs thus averaged $81 \pm 10 \%, 85 \pm 2 \%$, and $87 \pm 1 \%$ for total ammonia, $56 \pm 9 \%, 60 \pm 2 \%$, and $60 \pm 1 \%$ for orthophosphate, $32 \pm 9 \%$, $38 \pm 3 \%$, and $38 \pm 4 \%$ for DOC, $49 \%, 37 \%$, and $39 \%$ for total coliforms, and $41 \%, 50 \%$, and $41 \%$ for $E$. coli (see Fig. S5 $†$ for asymmetrical confidence intervals for total coliforms and $E$ coli), respectively. On all VFSs, removal was greatest for total ammonia ( $84 \pm 5 \%$ ) followed by $17 \alpha-\mathrm{TBOH}(72 \pm 3 \%)$, orthophosphate $(59 \pm 4 \%)$, E. coli $(44 \%)$, total coliforms $(42 \%)$, and DOC $(37 \pm 4 \%)$. These removal efficiencies are consistent with previous studies examining attenuation of manure-derived constituents on VFS. ${ }^{42-46,58}$

Because flow rates were similar on all VFS, mass loadings (i.e., $\mathrm{ng} \mathrm{m}^{-2}$ or $\mathrm{mg} \mathrm{m}^{-2}$ ) on the 4 and $5 \mathrm{~m} \mathrm{VFSs} \mathrm{were} 75 \%$ and $60 \%$ of the $3 \mathrm{~m}$ VFS mass loading. Therefore, we expected higher removal efficiencies on longer VFS given their longer hydraulic retention times and larger potential soil-water interfacial areas. However, removal efficiencies were surprisingly consistent for nutrients and DOC across these length scales $(83$ $\pm 3 \%, 59 \pm 4 \%$, and $38 \pm 5 \%$ for ammonia, orthophosphate, and DOC, respectively; Fig. 3 and 4) not only for the July 3 trial, but also in the other trials (Fig. S2-S4†). Therefore, for a given event, the removal performance is independent of loading. Between events, removal efficiencies were statistically different (one-way ANOVA, $F(3,14)=39.1, P<0.001$ ), varying from $68-$ $88 \%$ for $17 \alpha-\mathrm{TBOH}$. While it is reasonable to expect the performance to decrease with higher leachate concentrations, the performance was independent of the initial concentration. Surprisingly, the VFS treatment efficiency was statistically identical when $17 \alpha$-TBOH leachate concentrations were either 11 or $150 \mathrm{ng} \mathrm{L}^{-1}$ (88 or $83 \%$ removal, respectively) and when leachate concentrations were either 34 or $112 \mathrm{ng} \mathrm{L}^{-1}$ (72 or $68 \%$ removal, respectively), although removal was statistically lower in the latter group (Fig. 4). Although suspended solids were not measured directly, the performance was the lowest when the suspended solid content was qualitatively highest (i.e., 31 May, Fig. 4), suggesting a potential inverse relationship between suspended solids and removal. Thus, optimizing removal might focus upon suspended solids, DOC and colloid reduction in runoff. Conversely, if transport was limited by partitioning kinetics, increasing system hydraulic retention times (i.e. increased length or decreased slope) should be an effective management strategy.

\section{Transport potential}

In all experiments, $17 \alpha$-TBOH was easily the most abundant TBA metabolite in leachate, with $17 \beta-\mathrm{TBOH}$ and твO detected in leachate samples at concentrations below $5 \mathrm{ng} \mathrm{L}{ }^{-1}$, even when $17 \alpha$-ТВOH concentrations exceeded $150 \mathrm{ng} \mathrm{L^{-1 }}$. While it seems reasonable to assume negligible contributions of $17 \beta-$ ТВОН and ТВO to ecosystem risk, metabolite interconversion occurs readily. ${ }^{13,20,35}$ While $17 \beta-\mathrm{TBOH}$ and TBO were detected at low concentrations in this study and in our previous work, both have been detected in agricultural runoff at concentrations up to 270 and $35 \mathrm{ng} \mathrm{L}^{-1}$, respectively. ${ }^{14-16,40}$ In those systems (i.e., CAFOs and manure fertilized fields), TBA metabolites accumulated in surface soils, and microbial processes formed $17 \beta-$ ТВОН and ТВО from $17 \alpha-\mathrm{TBOH} .{ }^{35,59}$ Given the similar chemical properties of TBA metabolites, their environmental fate and transport behavior also should be conserved and we expect that 
these $17 \alpha$-TBOH observations are valid for all TBA metabolites and even other steroids with similar properties.

Vegetative filter strips are widely used to manage contaminants in agricultural runoff, particularly for sediment and nutrient control. Our results indicate that VFSs were effective at attenuating $17 \alpha$-TBOH over $\sim 1$ hour time scales, with an average $78 \%$ removal from surface runoff from all four experiments (Fig. 3, 4, S2 and S3†). It is commonly perceived that a single large strip is better than a small one; however, our results clearly indicate that small VFSs are highly effective, at least over short time scales and could be deployed within pastures near manure "hotspots" (i.e., cattle congregation points) to control contaminant transport near sources. Nichols et al. observed an $\sim 20 \%$ increase in $17 \beta$-estradiol removal when VFS lengths were increased from 3 to 18 meters, suggesting that removal was limited by equilibrium kinetics. ${ }^{52}$ While an $18 \mathrm{~m}$ VFS may be impractical, multiple shorter treatment systems in series might prove to be an equally effective management strategy.

While most $17 \alpha$-TBOH mass was retarded within the VFS, approximately $20 \%$ of the mass was readily mobile, a trend also observed for nutrients and DOC (Fig. 3 and S2-S4 $\dagger$ ). After VFS treatment, $17 \alpha$-TBOH runoff concentrations ranged from 1-43 $n g \mathrm{~L}^{-1}$. While NOAELs for aquatic vertebrates remain unclear, a reasonable estimate for TBA metabolites is $1 \mathrm{ng} \mathrm{L}^{-\mathbf{1}} \mathbf{. 8 , 1 1 , 1 2}^{\mathbf{8}}$ Therefore, concurrent dilution and attenuation are typically necessary to achieve NOAELs, and a clear relationship exists between the treatment system performance and the dilution required to attain NOAELs (Fig. 5). For example, $17 \alpha-\mathrm{TBOH}$ concentrations of $350 \mathrm{ng} \mathrm{L^{-1 }}$ are reported for CAFO runoff. ${ }^{19}$

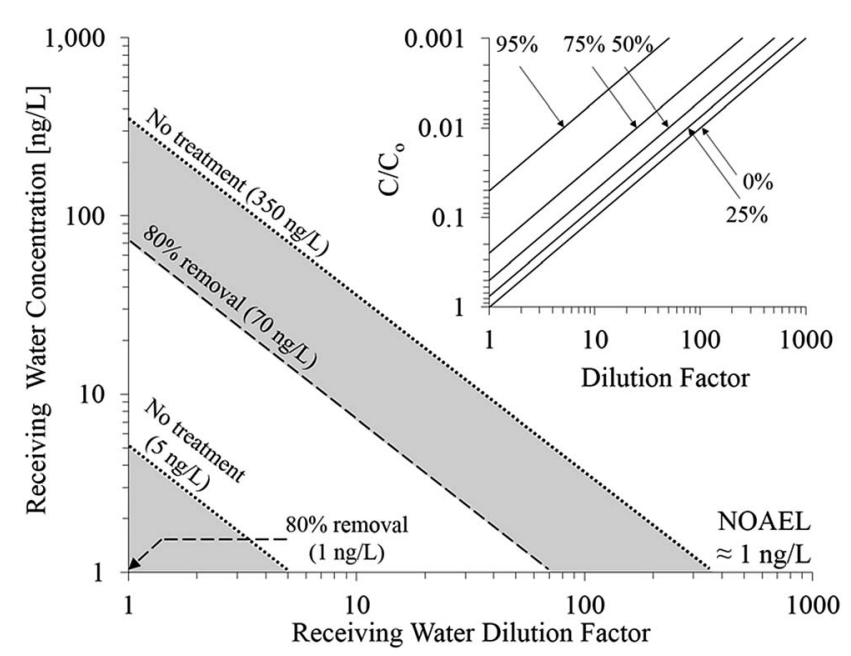

Fig. 5 Receiving water concentration of $17 \alpha-\mathrm{TBOH}$ as a function of runoff concentration, dilution capacity, and treatment performance. Dotted lines represent initial concentrations and dashed lines represent post-treatment concentrations in runoff assuming 80\% removal efficiencies. The assumed no observed adverse effect level (NOAEL) is $1 \mathrm{ng} \mathrm{L^{-1 }}$. Dilution likely is required to achieve receiving water concentrations of $1 \mathrm{ng} \mathrm{L}^{-1}$ when pre-treatment runoff concentrations exceed $5 \mathrm{ng}$ L. (Inset) Predicted concentrations (i.e., $C / C_{0}, y$-axis) in receiving waters as a function of treatment system performance (percent removal, lines) and the available dilution capacity of the receiving water ( $x$-axis).
Without attenuation, a dilution factor (the ratio of receiving water to runoff volumes or flows) of 350 is required to attain 1 ng $\mathrm{L}^{-1}$ NOAELs in receiving waters. Using a VFS with $80 \%$ removal efficiency, the required dilution factor is reduced proportionally, from 350 to 70, representing a substantial savings in the necessary dilution capacity. Ideally, treatment processes can attenuate concentrations to NOAELs without dilution, which should be true for runoff concentrations below $5 \mathrm{ng} \mathrm{\textrm {L } ^ { - 1 }}$ and VFS performance of $\sim 80 \%$ (Fig. 5). The reality of the nonpoint source pollution is that dilution often plays a critical role in mitigating ecosystem risk. Thus, understanding leachate concentrations, VFS performance, and receiving-water flows can identify risky periods or conditions, particularly when dilution volumes are low, where concentrations are most likely to exceed NOAELs. In general, first-order streams, wetlands, ephemeral pools, and other small waters with dilution capacities $<70-100$ are at the greatest risk from endocrine disrupting steroids. While the treatment efficacy must increase as the dilution capacity decreases to meet concentration-dependent performance goals, this relationship does not apply to mass-dependent performance goals like TMDLs. Future research should attempt to further develop these management relationships while optimizing non-point source pollution treatment strategies for steroids and other problematic contaminants.

\section{Conclusion}

In both surface and subsurface experiments, 17 $\alpha-\mathrm{TBOH}$, ammonia, orthophosphate, DOC, and coliforms were present within initial runoff samples, indicating that some of this constituent mass was highly mobile and traveled at or near the velocity of water. While retardation was clearly evident for all constituents, our data suggest that non-equilibrium partitioning processes likely facilitated the rapid transport of these constituents through these systems. Comparatively, however, contaminant breakthrough occurred more rapidly within the subsurface compared to the surface VFS, and we attribute the increased removal within the surface to the increased near surface biologic productivity and organic matter. While these data suggest that subsurface transport can increase the risk of aquatic ecosystem exposure to endocrine disrupting compounds, dominant processes responsible for the observed attenuation remain unclear, and additional mechanistic characterization of removal processes is needed.

Our results indicate that the transport potential of TBA metabolites through VFSs increased with increasing leachate concentrations, although the removal efficiency may depend on other factors such as TSS. The $17 \alpha$-TBOH removal efficiency was similar among all four VFS experiments (68-88\% removal). Previously, we reported that the $17 \alpha-\mathrm{TBOH}$ leaching potential peaked between 5 and 30 days post-implantation, with a 14400 and $4000 \mathrm{ng}$ per animal unit leaching potential during a $5 \mathrm{~cm}$ rainfall event and a 9 hour irrigation event, respectively. ${ }^{40}$ If $20 \%$ of $17 \alpha-\mathrm{TBOH}$ mass is readily mobile and unlikely to be attenuated during treatment, 800-2900 $\mathrm{ng}$ per AU is available for transport to receiving waters. Depending on rainfall and irrigation rates, the runoff or discharge concentrations will vary 
and will be system-dependent, but can be estimated and compared against desired exposure concentrations in receiving waters to assess the ecological risks to particular receiving waters. Therefore, to fully characterize the risks associated with TBA use, or the risks of other steroids and manure-derived contaminants in agro-ecosystems, we recommend the simultaneous evaluation of leaching, transport, and hydrologic characteristics as an appropriate strategy for prioritizing the implementation of runoff treatment technologies and selecting effective best management practices.

\section{Acknowledgements}

This research was kindly supported by the U.S. Department of Agriculture (NIFA Grant \#2010-65102-20407), a Grant-In-Aid of Research from Sigma Xi: the Scientific Research Society, and the UNR Graduate Student Association. We also thank many field assistants and the staff at SFREC, especially Nikolas Schweitzer and Dustin Flavell. We also thank Tye Morgan, Fay Allen, Jacob Phillips, and Robert Blank from the USDA-ARS Great Basin Rangelands Research Unit for analyzing soil samples.

\section{References}

1 E. F. Orlando, A. S. Kolok, G. A. Binzcik, J. L. Gates, M. K. Horton, C. S. Lambright, L. E. Gray Jr, A. M. Soto and L. J. Guilette Jr, Environ. Health Perspect., 2004, 112, 353-358.

2 A. M. Soto, J. M. Calabro, N. V. Prechtl, A. Y. Yau, E. F. Orlando, A. Daxenberger, A. S. Kolok, L. J. Guillette Jr, B. le Bizec, I. G. Lange and C. Sonnenschein, Environ. Health Perspect., 2004, 112, 346-352.

3 L. R. Iwanowicz, V. S. Blazer, C. P. Guy, A. E. Pinkney, J. E. Mullican and D. A. Alvarez, Environ. Toxicol. Chem., 2009, 28, 1072-1083.

4 J. K. Leet, L. S. Lee, H. E. Gall, R. R. Goforth, S. Sassman, D. A. Gordon, J. M. Lazorchak, M. E. Smith, C. T. Jafvert and M. S. Sepúlveda, Environ. Sci. Technol., 2012, 46, 13440-13447.

5 I. R. Falconer, H. F. Chapman, M. R. Moore and G. Ranmuthugala, Environ. Toxicol., 2006, 21, 181-191.

6 V. S. Blazer, L. R. Iwanowicz, H. Henderson, P. M. Mazik, J. A. Jenkins, D. A. Alvarez and J. A. Young, Environ. Monit. Assess., 2012, 184, 4309-4334.

7 G. T. Ankley, K. M. Jensen, E. A. Makynen, M. D. Kahl, J. J. Korte, M. W. Hornung, T. R. Henry, J. S. Denny, R. L. Leino, V. S. Wilson, M. C. Cardon, P. C. Hartig and L. E. Gray, Environ. Toxicol. Chem., 2003, 22, 1350-1360.

8 D. H. Miller and G. T. Ankley, Ecotoxicol. Environ. Saf., 2004, 59, 1-9.

9 K. M. Jensen, E. A. Makynen, M. D. Kahl and G. T. Ankley, Environ. Sci. Technol., 2006, 40, 3112-3117.

10 J. E. Morthorst, H. Holbech and P. Bjerregaard, Aquat. Toxicol., 2010, 98, 336-343.

11 R. J. Williams, V. D. J. Keller, A. C. Johnson, A. R. Young, M. G. R. Holmes, C. Wells, M. Gross-Sorokin and R. Benstead, Environ. Toxicol. Chem., 2009, 28, 220-230.
12 D. J. Caldwell, F. Mastrocco, P. D. Anderson, R. Länge and J. P. Sumpter, Environ. Toxicol. Chem., 2012, 31, 1390-1406. 13 B. Schiffer, A. Daxenberger, K. Meyer and H. H. Meyer, Environ. Health Perspect., 2001, 109, 1145.

14 H. E. Gall, S. A. Sassman, L. S. Lee and C. T. Jafvert, Environ. Sci. Technol., 2011, 45, 8755-8764.

15 H. E. Gall, S. A. Sassman, B. Jenkinson, L. S. Lee and C. T. Jafvert, Hydrol. Processes, 2014, 28, 1318-1328.

16 S. L. Bartelt-Hunt, D. D. Snow, W. L. Kranz, T. L. Mader, C. A. Shapiro, S. J. van Donk, D. P. Shelton, D. D. Tarkalson and T. C. Zhang, Environ. Sci. Technol., 2012, 46, 1352-1360.

17 B. Khan and L. Lee, Chemosphere, 2012, 89, 1443-1449.

18 J. A. Parker, J. P. Webster, S. C. Kover and E. P. Kolodziej, Talanta, 2012, 99, 238-246.

19 J. P. Webster, S. C. Kover, R. J. Bryson, T. Harter, D. S. Mansell, D. L. Sedlak and E. P. Kolodziej, Environ. Sci. Technol., 2012, 46, 3803-3810.

20 B. Schiffer, K. U. Totsche, S. Jann, I. Kögel-Knabner, K. Meyer and H. H. D. Meyer, Sci. Total Environ., 2004, 326, 225-237.

21 L. S. Lee, T. J. Strock, A. K. Sarmah and P. S. C. Rao, Environ. Sci. Technol., 2003, 37, 4098-4105.

22 B. Khan, X. Qiao and L. S. Lee, Environ. Sci. Technol., 2009, 43, 8827-8833.

23 X. Qiao, N. Carmosini, F. Li and L. S. Lee, Environ. Sci. Technol., 2011, 45, 3989-3995.

24 M. L. Card, Y.-P. Chin, L. S. Lee and B. Khan, J. Agric. Food Chem., 2012, 60, 1480-1487.

25 F. X. M. Casey, G. L. Larsen, H. Hakk and J. Šimůnek, Environ. Sci. Technol., 2003, 37, 2400-2409.

26 F. X. M. Casey, H. Hakk, J. Šimůnek and G. L. Larsen, Environ. Sci. Technol., 2004, 38, 790-798.

27 F. X. M. Casey, J. Šimůnek, J. Lee, G. Larsen and H. Hakk, J. Environ. Qual., 2005, 34, 1372-1379.

28 J. Mansell and J. E. Drewes, Groundwater Monit. Rem., 2004, 24, 94-101.

29 B. Stumpe and B. Marschner, Sci. Total Environ., 2007, 374, 282-291.

30 S. van Donk, S. Biswas, W. Kranz, D. Snow, S. Bartelt-Hunt, T. Mader, C. Shapiro, D. Shelton, D. Tarkalson, T. Zhang and S. Ensley, Trans. ASABE, 2013, 56, 1327-1338.

31 H. Sangsupan, D. Radcliffe, P. Hartel, M. Jenkins, W. Vencill and M. Cabrera, J. Environ. Qual., 2006, 35, 2261-2272.

32 E. W. Peterson, H. A. Orndorff and R. K. Davis, J. Environ. Qual., 2000, 29, 826-834.

33 S. Arnon, O. Dahan, S. Elhanany, K. Cohen, I. Pankratov, A. Gross, Z. Ronen, S. Baram and L. Shore, Environ. Sci. Technol., 2008, 42, 5521-5526.

34 B. Khan, L. S. Lee and S. A. Sassman, Environ. Sci. Technol., 2008, 42, 3570-3574.

35 B. Khan and L. S. Lee, Chemosphere, 2010, 79, 873-879.

36 E. Kolodziej, S. Qu, K. Forsgren, S. Long, J. Gloer, G. D. Jones, D. Schlenk, J. Baltrusaitis and D. Cwiertny, Environ. Sci. Technol., 2013, 47, 5031-5041.

37 S. Qu, E. P. Kolodziej, S. A. Long, J. B. Gloer, E. V. Patterson, J. Baltrusaitis, G. D. Jones, P. V. Benchetler, E. A. Cole, 
K. C. Kimbrough, M. D. Tarnoff and D. M. Cwiertny, Science, 2013, 342, 347-351.

38 E. J. Durhan, C. S. Lambright, E. A. Makynen, J. Lazorchak, P. C. Hartig, V. S. Wilson, L. E. Gray and G. T. Ankley, Environ. Health Perspect., 2006, 114, 65-68.

39 A. S. Kolok, D. D. Snow, S. Kohno, M. K. Sellin and L. J. Guillette Jr, Sci. Total Environ., 2007, 388, 104-115.

40 G. D. Jones, P. V. Benchetler, K. W. Tate and E. P. Kolodziej, Environ. Sci. Technol., 2014, 48, 3715-3723.

41 A. T. O'Geen, R. A. Dahlgren, A. Swarowsky, K. W. Tate, D. J. Lewis and M. J. Singer, Calif. Agric., 2010, 64, 77-84.

42 I. Chaubey, D. Edwards, T. Daniel, P. Moore and D. Nichols, Trans. ASAE, 1994, 37, 845-856.

43 I. Chaubey, D. Edwards, T. Daniel, P. Moore and D. Nichols, Trans. ASAE, 1995, 38, 1687-1692.

44 T. Lim, D. Edwards, S. Workman, B. Larson and L. Dunn, Trans. ASAE, 1998, 41, 1375-1381.

45 A. K. Knox, K. W. Tate, R. A. Dahlgren and E. R. Atwill, Calif. Agric., 2007, 61, 159-165.

46 K. Tate, G. Nader, D. Lewis, E. Atwill and J. Connor, J. Soil Water Conserv., 2000, 55, 473-478.

47 G. D. Jones, P. V. Benchetler, K. W. Tate and E. P. Kolodziej, Environ. Sci. Technol., 2014, DOI: 10.1021/es503406h.
48 H. Dizer, B. Fischer, I. Sepulveda, E. Loffredo, N. Senesi, F. Santana and P. D. Hansen, Environ. Toxicol., 2002, 17, 105-112.

49 R. D. Holbrook, N. G. Love and J. T. Novak, Environ. Sci. Technol., 2004, 38, 3322-3329.

50 Y. Zou and W. Zheng, Environ. Sci. Technol., 2013, 47, 51855192.

51 F. A. Coutelieris, M. E. Kainourgiakis and A. K. Stubos, J. Colloid Interface Sci., 2003, 264, 20-29.

52 D. J. Nichols, T. C. Daniel, D. R. Edwards, P. A. Moore and D. H. Pote, J. Soil Water Conserv., 1998, 53, 74-77.

53 E. R. Atwill, L. Hou, B. M. Karle, T. Harter, K. W. Tate and R. A. Dahlgren, Appl. Environ. Microbiol., 2002, 68, 55175527.

54 M. Abu-Zreig, R. P. Rudra, H. R. Whiteley, M. N. Lalonde and N. K. Kaushik, J. Environ. Qual., 2003, 32, 613-619.

55 C. H. Lin, R. N. Lerch, K. W. Goyne and H. E. Garrett, J. Environ. Qual., 2011, 40, 791-799.

56 J. H. Stagge, A. P. Davis, E. Jamil and H. Kim, Water Res., 2012, 46, 6731-6742.

57 J. H. Writer, J. N. Ryan and L. B. Barber, Environ. Sci. Technol., 2011, 45, 7275-7283.

58 R. K. Koelsch, J. C. Lorimor and K. R. Mankin, Appl. Eng. Agr., 2006, 22, 141-153.

59 E. Cole, Master's Thesis, University of Nevada Reno, 2013. 